\title{
GESTÃO MUNICIPAL E AÇÕES INTEGRADAS PARA O FORTALECIMENTO DO TURISMO NO TERRITÓRIO QUARTA COLÔNIA, RS, BRASIL
}

\author{
MUNICIPAL MANAGEMENT AND INTEGRATED ACTIONS TO STRENGTHEN TOURISM IN THE \\ TERRITORY OF QUARTA COLÔNIA, RS, BRAZIL
}

\begin{abstract}
GESTIÓN MUNICIPAL Y ACCIONES INTEGRADAS PARA EL FORTALECIMIENTO DEL TURISMO EN EL TERRITORIO QUARTA COLÔNIA, RS, BRASIL
\end{abstract}

Dalva Maria Righi Dotto Universidade Federal de Santa Maria - UFSM Doutora em Desenvolvimento Regional dalvadotto@gmail.com

Adriele Carine Menezes Denardin Universidade Federal de Santa Maria - UFSM

Bacharel em Administração dricadenardin@hotmail.com

Mônica Elisa Dias Pons Universidade Federal de Santa Maria - UFSM Doutora em Comunicação Social monica@ufsm.br

Caroline Ciliane Ceretta Universidade Federal de Pelotas - UFPEL Doutora em Extensão Rural carolineceretta@hotmail.com

Data de Submissão: 26/04/2017 Data de Aprovação: 16/10/2017

RESUMO: Como elemento de desenvolvimento local, o turismo pode tomar a forma de roteiros integrados, estimulados pela governança local, com a oferta de bens e serviços para compor o produto turístico em parceria com a iniciativa privada. Este artigo tem como propósito analisar em que medida a atividade de turismo é compreendida como parte das discussões em torno do desenvolvimento da Quarta Colônia/RS/Brasil, uma vez que as lideranças políticas dos municípios usufruem de uma narrativa que o reconhece como parte integrada na perspectiva territorial de desenvolvimento. Os objetivos são identificar as principais ações em torno da atividade turística pensada de forma integrada no território Quarta Colônia; conhecer a visão da gestão pública sobre o uso do turismo como estratégia de desenvolvimento do território; e identificar se existem e como são realizadas as ações integradas para o fortalecimento do turismo no território. O estudo constitui uma perspectiva qualitativa de investigação, com aplicação de entrevistas semiestruturadas nas secretarias municipais de turismo desta região e análise descritiva e de discurso das informações obtidas. Os resultados da pesquisa demonstraram que a gestão do turismo nos municípios da região encontra-se desarticulada, com atuação discreta do poder público, refletindo em ações dispersas e com planejamento precário.

PALAVRAS-CHAVE: turismo, desenvolvimento turístico, gestão pública municipal, Quarta Colônia/ RS.

ABSTRACT: As an element of local development, tourism can take the form of integrated road maps, stimulated by local governance through the offer of goods and services, in order to compose the touristic product in partnership with the private initiative. This article analyzes the extent to which tourism is seen as a part of the discussions around the development of Quarta Colônia in the State of Rio Grande do Sul, Brazil, given that the political leaders of the municipalities employ a narrative that recognizes tourism as an integrated part of the prospects for development. The objectives are to identify the main actions around tourism, viewed in an integrated way, in the territory of Quarta 
ISSN: 1983-7151

Colônia; to investigate the views of the public management on the use of tourism as a strategy for the development of the territory; and to identify the existence and form of integrated actions to strengthen tourism within the territory. This study represents a qualitative research perspective, with the application of semi-structured interviews in the municipal tourism departments of this region, with descriptive analysis and discourse evaluation of the information obtained. The results of the research showed that the tourism management in the municipalities of the region is disjointed, with minimal effectiveness of the public authorities in this regard, resulting in dispersed actions and a lack of planning.

KEYWORDS: tourism, tourism development, municipal management, Quarta Colônia/ RS.

RESUMEN: Como elemento de desarrollo local, el turismo puede tomar la forma de itinerarios integrados, estimulados por el gobierno local con la oferta de bienes y servicios para componer el producto turístico en conjunto con la iniciativa privada. Este artículo tiene como propósito analizar en qué medida la actividad de turismo es comprendida como parte de las discusiones alrededor del desarrollo de la Quarta Colônia/RS/Brasil, considerando que los liderazgos políticos de los municipios gozan de una narrativa que los reconocen como parte integrada desde la perspectiva territorial de desarrollo. Los objetivos son identificar las principales acciones en torno de la actividad turística pensada de forma integrada en el territorio Quarta Colônia; conocer la visión de la gestión pública sobre el uso del turismo como estrategia de desarrollo del territorio; e identificar si existen y cómo se realizan las acciones integradas para el fortalecimiento del turismo en el territorio. El estudio constituye una perspectiva cualitativa de investigación, con aplicación de entrevistas semiestructuradas en las secretarías municipales de turismo de esta región y análisis descriptivo y de discurso de las informaciones obtenidas. Los resultados de la investigación demostraron que la gestión del turismo en los municipios de la región se encuentra desarticulada, con actuación discreta del poder público, reflejándose en acciones dispersas y con planeamiento precario.

PALABRAS CLAVE: Turismo; Desarrollo turístico; Gestión pública municipal; Quarta Colônia/ RS.

INTRODUÇÃO

or ser um produto capaz de agregar valor à cadeia produtiva
estabelecida, o turismo em sua plenitude tem oportunizado a
geração de empregos e perspectivas socioeconômicas locais, motivo do qual se expandiu e continua expandindo-se na esfera global sem precedentes. A emergência de um novo turismo, plural e com responsabilidade ambiental nas suas ações no início dos anos de 1990, tem apontado para uma economia de valor capaz de buscar elementos inovadores na sua cadeia produtiva. Além disso, a atividade turística tem buscado cumprir parte de seu papel de responsabilidade ambiental, reconhecendo que os recursos existentes nos municípios também identificam um território espacial e culturalmente construído. Nos territórios com força atrativa, a atividade de turismo emerge como uma estratégia de agregar valor às economias locais e, principalmente, potencializando a valorização dos recursos culturais e naturais como estratégia identitária de desenvolvimento territorial (Pecqueur, 2005).

No Brasil, a retomada do turismo como uma atividade comprometida com o desenvolvimento sustentável da atividade ainda não tem a totalidade pretendida, 
mas já marca o início de uma nova expectativa, cujos efeitos globais da prática de um turismo massivo, desordenado e sem limites que marcaram os anos de 1950 a 1980 no país, vão sendo superados com o incentivo principalmente nas parcerias público-privadas para efetivar o planejamento e a gestão da atividade (Beni, 2006).

Como elemento de desenvolvimento local, o turismo deve primar pela responsabilidade de usufruir dos recursos locais existentes e, a partir de uma gestão responsável e integrada, constituir com os atores sociais locais um processo de sensibilização capaz de reconhecer o valor turístico em construção (Sabourin, 2009). Para tal, as práticas da atividade junto aos territórios por vezes tomam a forma de roteiros integrados, estimulados pela governança local e dispostos a buscar no próprio entorno a oferta de bens e serviços para compor o produto turístico.

Neste aspecto, o território Quarta Colônia, no centro do estado do Rio Grande do Sul, tem usufruído de seus recursos identitários para divulgar e comercializar seus produtos turísticos. No entanto, apesar da perspectiva territorial compor a dinâmica que concebe as narrativas territoriais de desenvolvimento para os municípios membros da Quarta Colônia, o que se tem observado é um significativo enfraquecimento das ações e das iniciativas das lideranças locais em torno do desenvolvimento do turismo (Silva, 2014). Há algo que necessita ser contemplado que revele algo a mais, do que se escuta nas narrativas sobre o desenvolvimento integrado, pois muitos roteiros e rotas turísticas estimulados na década de 2000 sequer saíram do papel ou de seus fôlderes, e os que já saíram ainda se apresentam deficitários para sua comercialização. Apesar de forte apelo turístico da região e embora as lideranças apostem em narrativas de desenvolvimento turístico, na prática, pouco se visualiza no território (Silva, 2014).

Assim, este estudo tem como objetivo principal analisar em que medida a atividade de turismo é compreendida como parte das estratégias do desenvolvimento territorial da Quarta Colônia, uma vez que as lideranças políticas dos municípios usufruem de uma narrativa que o reconhece como parte integrada da perspectiva territorial de desenvolvimento. Especificamente, os objetivos são identificar as principais ações em torno da atividade turística 
pensada de forma integrada no território Quarta Colônia; conhecer a visão da gestão pública sobre o uso do turismo como estratégia de desenvolvimento do território; e identificar se existem e como são realizadas as ações integradas para o fortalecimento do turismo no território.

Metodologicamente, este estudo se apresenta como um artigo de corte qualitativo e de caráter exploratório-descritivo. A coleta de dados se deu em fontes secundárias formadas por materiais que já receberam tratamento analítico; e em fontes primárias, por meio de entrevistas nos locais de campo empírico. O tratamento analítico das informações foi realizado por meio de análise descritiva e de discurso.

Estruturalmente, este artigo se apresenta composto por três eixos, sendo o primeiro para constituir o aporte teórico, um segundo eixo que traz os resultados investigativos e, por fim, um terceiro eixo que transcende a teoria-prática concebida para constituir os principais aspectos reflexivos da investigação. Espera-se que o estudo sirva como base para uma perspectiva de novos sentidos e ações estratégicas para o desenvolvimento do turismo no território Quarta Colônia/RS.

\section{FUNDAMENTAÇÃO TEÓRICA}

\section{O TURISMO E O ÂMBITO LOCAL: PERSPECTIVAS TERRITORIAIS DE DESENVOLVIMENTO}

Pelo sexto ano consecutivo, o turismo apresentou crescimento positivo em torno de 3,1\% no ano de 2015, contribuindo com um total de US $\$ 7.2$ trilhões para o PIB mundial, representando algo em torno de 9,8\% do PIB total. Já em 2016, a contribuição do setor para o PIB está estimada em um crescimento de $3,3 \%$, em que o setor de Viagens e Turismo poderá superar a economia global ao longo da próxima década, crescendo a uma taxa média de $4 \%$ ao ano nos próximos 10 anos (WTTC - World Travel and Tourism Council, 2016). Estima-se que diversos países sigam em crescimento direto do PIB de viagens e turismo nos próximos anos, enquanto que para a América Latina, em especial o Brasil, a 
expectativa é que o crescimento seja reduzido por conta da conjuntura política, econômica e estrutural do mercado brasileiro. Embora seja uma perspectiva não tanto favorável para o setor de turismo, a atividade segue como promissora alternativa de desenvolvimento, reunindo atributos de renda, de trabalho, de emprego, de valorização cultural, de diversificação produtiva e de forte presença no movimento global, capaz de valorizar diferentes dimensões da realidade social para o desenvolvimento dos territórios que dele se apropriarem (Kotler et al., 2006). Para os autores, a natureza multiplicadora e compósita da atividade turística é reflexo da evolução da sociedade capitalista, evidenciando múltiplas oportunidades em suas diversas inserções nos destinos consagrados ou não. Os novos agentes e atores sociais são impulsionados por diferentes motivações e iniciativas junto ao cenário global, para consumir uma gama de produtos e serviços turísticos com destacada qualificação para fidelizar turistas que se deslocam dos mais variados destinos o ano todo (Kotler et al., 2006).

A natureza multiplicadora e compósita do turismo reflete a evolução da sociedade capitalista, evidenciando múltiplas oportunidades tanto para os destinos consagrados como para os que emergem atualmente. Nas últimas décadas, a globalização, a urbanização, a explosão demográfica, o desenvolvimento científico e tecnológico, as novas estruturas econômicas e, particularmente, a ampliação do poder aquisitivo de uma parcela considerável da população, mudaram a relação entre visitantes e visitados, hóspedes e anfitriões (Beni, 2006). O acesso à informação, à tecnologia, à cultura, ao fluxo de ideias e ao conhecimento fez com que a hospitalidade em torno do turismo seguisse nos debates atuais. Sua capacidade de articulação e movimentação, inter e transdisciplinar, desencadeada pelo movimento social característico do setor turístico, tem sido um dos principais aliados deste processo.

De forma intrínseca, o turismo tem se tornado um dos agentes motivadores para reunir esforços civis e governamentais com o intuito de defender a inclusão social, gerar emprego, valorizar a cultura, respeitar as diferenças, diversificar a renda familiar em localidades periféricas, além de ser um importante ativo na dinâmica socioambiental do desenvolvimento dos territórios (Sacco dos Anjos \& Caldas, 2009). É neste cenário que, na contemporaneidade, o local de sentido territorial e não localista emerge como protagonista para uma nova gestão da 
atividade, buscando na hospitalidade dos destinos encontrar um diferencial para a oferta de produtos, já que equipamentos e conforto não são mais os principais fatores de diferenciação e escolha dos destinos.

Na dimensão global, destacar-se-ão os países que conseguirem articular seus sistemas produtivos com alta competitividade em mercados globais, bem como os que conseguirem planejar o potencial turístico. Esta potencialização emergirá em meio à institucionalização de parcerias e alianças público-privadas como poderosos instrumentos para atingir a desejável articulação em redes de cooperação produtiva, como forma de consolidar o desenvolvimento sustentável (BENI, 2006). Corroborando com o entendimento de que as parcerias públicoprivadas são importantes, Aranda et al. (p. 67, 2017) afirmam que muitos países optaram por incorporar nas matrizes econômicas o setor de turismo e que os efeitos positivos podem ser evidenciados quando existe uma "gestión armónica y participativa de los entes involucrados, generándose utilidades que se revierten en la calidad de vida de las comunidades, la dinámica de las economías y la satisfacción de los clientes externos".

Nesse aspecto, o desafio da atividade turística aparece junto às articulações organizacionais, as políticas institucionais e, principalmente, as estratégias mercadológicas priorizadas, que de forma integradas deverão assumir a perspectiva territorial de desenvolvimento, atrelada à contínua sustentabilidade das ações e das relações entre os indivíduos. Embora neste cenário também estejam presentes aspectos que inibem a sustentabilidade destinada ao setor, principalmente pela presença de grandes componentes poluentes de transporte, competições mercadológicas no uso dos recursos não renováveis e o consumismo exagerado de riquezas. Cooper (2007) aponta que aspectos econômicos, ambientais, socioculturais, limites de capacidade de cargas irreais têm atuado contra o turismo sustentável, seja em momentos de estímulo à inflação, de poluição do ar pelas companhias aéreas, seja de massificação de turistas em comunidades locais que não se adaptam a nada e tratam de observar e incentivar a comercialização de produtos diferentes dos hábitos locais.

Ao mesmo tempo em que o turismo se tornou acessível para a população por conta da mobilidade global dos últimos anos, é no âmbito local que os impactos continuam sendo percebidos com maior contingência, pois no momento que o 
turista retorna de sua visita, os destinos absorvem as consequências, por vezes positivas, outras negativas das visitas realizadas.

Em função da diversidade de atrativos que compõem a oferta turística nos últimos tempos, a estruturação de roteiros turísticos tem sido uma possibilidade de estimular a sustentabilidade da atividade turística. De forma planejada, ambientalmente seguro e ao mesmo tempo competitivo mercadologicamente, os roteiros turísticos podem ser ofertados nos mais variados territórios. Bahl (2004) conceitua os roteiros como sendo a descrição pormenorizada de uma viagem ou itinerário com indicação de uma sequência de atrativos existentes e merecedores de visita. Assim, a importância de se estruturar um roteiro turístico não está somente no fato de cumprir a visita a um determinado número de atrativos e estabelecimentos comerciais sequenciais, mas sim o quanto foi impactado positiva ou negativamente o espaço visitado e seu conteúdo sociocultural.

Tavares (2002) afirma que criar um roteiro turístico vai além da elaboração de um cronograma de atividades associadas a uma logística de transporte e alimentação, pois em tempos de cultura e informação intelectualizadas a concepção de um roteiro turístico deverá oportunizar um percurso capaz de ser lido, apreciado e conduzido a um olhar de construção territorial. Pela sua inserção social e econômica no destino, os roteiros turísticos geralmente resultam de iniciativas públicas, repassados às governanças estaduais e municipais na forma participativa de ação, em que poderão ser discutidas e articuladas com a comunidade todo processo de desenvolvimento que a atividade turística irá desencadear no âmbito local e regional.

Com o apoio do poder público, medidas simples podem solucionar impedimentos geográficos, de tráfego de veículos, normatização de horários, estacionamentos para visitantes próximos aos atrativos com estacionamento de ônibus de excursão; infraestrutura de acesso, sanitária, nos atrativos, entre outras. A ação pública ajuda na reurbanização de áreas de concentração de atrativos, no efetivo de policiamento presente nos locais de visitação e significativamente, na sensibilização para a qualificação profissional permanente daqueles que estarão direta e indiretamente envolvidos (Tavares, 2002). Com a função de contextualizar determinados atrativos e potencializar a atratividade e 
a presença de roteiros turísticos integrados, os destinos turísticos são valorizados no sentido direto de favorecimento da cadeia produtiva da atividade.

Nesse aspecto, o planejamento de um roteiro turístico tem nos recursos locais a matéria-prima necessária para compor uma atratividade diferenciada e, a partir disso, somar com as ações de sensibilização de atores locais para estruturar e formatar um itinerário composto por atrativos, informações, transportes, alimentação e hospedagem, compras e outras oportunidades decorrentes das demandas de visitantes.

No entanto, a relação entre o território e o turismo tem assumido alguns enfrentamentos não só conceituais, mas de ordem de organização física, social e política, o que se deve, principalmente, à falta de esclarecimento e mesmo qualificação dos atores para atender às exigências do turismo nos lugares de sua prática. Parte dos resultados da elaboração precária de muitos roteiros se deve às medidas e aos entendimentos equivocados entre as governanças públicas, desde a ordem conceitual da roteirização e da regionalização do turismo até a falta de informação nos portais de informação on-line (Beni, 2006). Fatos estes que têm contribuído para uma realidade pouco competitiva de muitos destinos, inclusive no Rio Grande do Sul, onde muitos roteiros seguem embrionários ou mesmo estagnados, além do que em muitos casos existe significativa precariedade de informações e amadorismo em relação à implantação da atividade desde as primeiras ações de criação (Jasper, 2012).

Todavia ainda existem outros roteiros turísticos no Estado que potencializaram seus ciclos de vida e seguem alavancados pela parceria público-privada, destacando-se no cenário nacional como atrativos turísticos competitivos internacionalmente, a exemplo dos roteiros da Serra Gaúcha, do Roteiro Delícias da Colônia no Vale do Taquari e do Circuito Internacional das Missões Jesuíticas, formado por uma Rota Turística Internacional que une o Brasil, a Argentina, o Paraguai e o Uruguai na constituição do mais importante produto turístico cultural do Mercosul. Este último circuito é considerado pela Unesco, desde 1995, como um dos principais Roteiros Históricos Internacional do Mundo, ao lado da Rota das Sedas na Ásia, da Rota Escrava no Caribe e do Mundo Maia na América Latina (Prefeitura Municipal de São Miguel das Missões, 2016; Nogueira \& Burkhard, 2008). 
Nestes roteiros, a iniciativa privada teve a flexibilidade de acenar positivamente na viabilização e na implantação dos roteiros de forma efetiva e competitiva para atender às exigências do público, reunindo estratégias de consumo do seu produto ofertado.

Beni (2006) afirma que muito dos problemas que impedem a comercialização de roteiros turísticos estão atrelados à falta de verba orçamentária e capital humano habilitado nos municípios ou destinos que buscam o turismo. A administração pública e gerencial destes roteiros pode ser uma oportunidade de minimizar a crise do estado e que estrategicamente terá na parceria públicoprivada criatividade, inovação e agilidade suficiente para potencializar o roteiro e encontrar solução efetiva de comercialização, ao mesmo tempo em que descentraliza e compartilha a gestão local.

Um roteiro turístico é uma oportunidade que a comunidade possa estar ativa no processo de construção social do território, atribuindo ao turismo um qualitativo de identidade e distinção do território de forma responsável. Nesse processo, as novas oportunidades em torno da relação entre o homem e o território buscam não somente legitimar a produção, a indústria e os serviços dos ambientes rurais e urbanos, mas também potencializar atividades capazes de agregar valor. Por exemplo, espera-se que no momento da inserção da atividade turística num destino ocorra a capacidade de multiplicação e distribuição de renda, e também a valorização da identidade local e outros efeitos evidenciados pela sua natureza compósita.

É no processo de desenvolvimento territorial que Pecqueur (2005) revela a possibilidade de novas estratégias de desenvolvimento em seu sentido construído e atrelado à valorização de atividades locais que permitem aos atores se reorganizarem nas novas economias emergentes atuais. Para o autor, a flexibilidade dos sistemas territoriais atuais, cujos atores devem estar pertencentes ao processo, e não somente representados, possivelmente irá identificar novos e diferentes modos de organização produtiva capaz de se tornar elementos de desenvolvimento local, como é o caso das atividades que acenarem para o uso do turismo. O turismo cultural, a gastronomia regional, o artesanato e outras atividades constituídas de valor cultural no território passam 
a compor alguns dos indicadores de desenvolvimento capazes de transformar os contextos locais, até então menos dinâmicos, econômica, política e socialmente (Beni, 2006).

Nesse processo, cada vez mais as 'economias de volumes' são cambiadas pelas 'economias de valor', consideradas mais favoráveis às virtudes encontradas nos produtos, nos processos e nos serviços com identidade cultural, que se manifesta no território a partir da revelação dos ativos intangíveis no tecido social, conforme justifica Sacco dos Anjos (2011).

Pecqueur (2005) acredita que, quando os recursos territoriais são explorados, organizados ou revelados, se tornam ativos territoriais, numa base teórica de envolvimento e iniciativas coletivas de atores sociais, de territórios interrelacionados onde existe, por um lado, o formato político-administrativo 'dado' e, por outro, o 'construído'

A partir do processo de atribuir valor aos recursos locais, Sacco dos Anjos (2003) refere-se ao turismo como sendo um indicativo capaz de provocar a transformação de recursos em ativos e, com isso, tornar-se elemento de desenvolvimento, desde que haja uma abordagem social conectada ao compromisso dos administradores locais em compartilhar as metodologias e as tecnologias para estimular o processo. Assim, há a necessidade de evidenciar o vínculo do turismo com a riqueza, o valor e a concepção do desenvolvimento, atrelado às relações sociais, culturais e historicamente construído entre os homens e o meio em que vivem, pois do contrário o processo de desenvolvimento fica fragilizado, não atingindo a sua plenitude.

Na perspectiva territorial, o turismo só terá condições de ser um novo fator de desenvolvimento local quando for reconhecido o valor de seus recursos identitários, nos quais os atores sociais são fundamentais para desencadear novas redes de políticas, de estrutura, conduta e desempenho, cujos ativos estarão atrelados ao valor atribuído por eles mesmos para constituir identidades e distintividades no território (Sabourin, 2009).

Froehlich e Alves (p.66, 2007) apontam que a "mobilização e o aproveitamento de recursos passam pela construção social das identidades locais e regionais, bem como pela valorização do patrimônio cultural e natural através de projetos 
de desenvolvimento", identificados como novos tipos de territorialidade. Projetos estes que tanto podem ser resultado de um processo institucionalizado, representativo de uma coletividade formal, ou de um grupo informalizado que individualmente os territorializa, protagonizando ambos programas e projetos de desenvolvimento locais e regionais. Assim, os programas e os projetos desenvolvidos no território poderão constituir normas e ações de turismo, cujo processo de desenvolvimento local terá em seus atores locais a responsabilidade de atuar sob o apoio da governança local como sujeitos ativos e responsáveis pelo sucesso ou fracasso decorrente (Silva, 2014).

A atividade turística como elemento de desenvolvimento local é um componente capaz de estimular estrategicamente o sistema produtivo local, reunindo em torno de uma demanda turística variáveis capazes de evidenciar melhoria de vida, bem-estar social; produzir o efeito multiplicador da renda; revitalizar e valorizar o patrimônio local; dar liberdade de ação; melhorar a infraestrutura básica e turística, bem como a superestrutura em torno do turismo, entre outros. Para Cooper (2007), o turismo é um verdadeiro catalisador de desenvolvimento, à medida que sua gestão seja capaz de equilibrar os usos aos princípios sustentáveis de ação.

Neste caso, o planejamento internacional, o nacional e o local devem contemplar ações conjuntas e afinadas, com políticas e interesses responsáveis de efeitos globais. Entretanto, é no âmbito local/regional que o desenvolvimento do turismo deverá ter suas ações específicas detalhadas e encorajadas para atender às responsabilidades ambientais acima de interesses lucrativos imediatistas e de impactos desastrosos. É preciso que os planos nacionais estejam alinhados aos projetos locais e incluir neste processo avaliações contínuas de viabilidade, expectativas e interesse público-privado.

Construir e acompanhar o processo de planejamento turístico em âmbito local significa compreender que o território é um espaço constituído por um conteúdo cultural cujos atores atuam para efetivar a sustentabilidade. Assim, reunir os recursos para constituir os roteiros são as premissas para um início de desenvolvimento da atividade turística, buscando no território aspectos identitários que constituam a diferença valorizada. 


\section{OS ASPECTOS METODOLÓGICOS E A ÁREA DE ESTUDO}

Metodologicamente, o estudo constitui uma perspectiva qualitativa de investigação, alcançando quanto à profundidade teórica o caráter exploratóriodescritivo. A investigação é inicialmente do tipo exploratória, em função da estratégia de verificar informações preliminares sobre a viabilidade do estudo e, num segundo momento, caracteriza-se pelo aprofundamento descritivo, para que possam ser descritas as informações observadas e recolhidas com segurança e clareza dos fatos da realidade (Gil, 2009; Triviños, 2011).

A coleta de dados aconteceu em dois momentos, sendo um priorizando os aspectos secundários compostos por obras, artigos e materiais bibliográficos e outro, valendo-se de fontes primárias, nos locais de campo empírico. As fontes primárias foram coletadas por meio de entrevistas, com roteiro semiestruturado junto aos representantes das Secretarias de Turismo dos municípios da Quarta Colônia. O período de coleta foi no ano de 2016 e contemplou a totalidade dos municípios da região (nove municípios). O tratamento analítico dos dados valeu-se de uma análise descritiva e de discurso, cujo desafio foi construir interpretações, pressupondo a captura do sentido oculto, das invisibilidades e das interações oriundas das entrevistas e dos seus conteúdos narrativos (Malhotra, 2012; Sampieri, 2013).

Com relação à área de estudo, a Quarta Colônia, no centro do estado do Rio Grande do Sul (RS), tem se destacado como um território promissor para o desenvolvimento doturismoemmeioà perspectivaterritorial dedesenvolvimento (Guimaraes, 2011). Os municípios da Quarta Colônia são formados por Silveira Martins, Ivorá, Nova Palma, Pinhal Grande, Faxinal do Soturno, São João do Polêsine, Dona Francisca, Restinga Seca e Agudo, e na totalidade compõem uma área de $2.923 \mathrm{~km}^{2}$ e abrigam um contingente de aproximadamente 63 mil habitantes (IBGE, 2010). Distante aproximadamente 30 quilômetros da cidade universitária de Santa Maria e cerca de onde ocorrem inúmeras referências de várias culturas ${ }^{1}$ que influenciam seus habitantes, principalmente, nos hábitos, costumes, gastronomia e artesanato dessa região.

1 Apesar da construção social da Quarta Colônia sustentar-se na narrativa da história da colonização italiana no território, a cultura alemã, a afrodescendente e a portuguesa presentes são reivindicadas politicamente pelo Condesus como diversidade de elementos culturais e multiplicidade étnica. No entanto, a coesão socioterritorial envolve constantes e dificultosas negociações inter-étnicas e intermunicipais, pois a narrativa histórica da colonização italiana que se sustenta fortemente no mito de origem e civilizador que constantemente é rememorada entre os descendentes, promovendo a valorização da etnicidade e dos significados do seu pertencimento no território (Froehlich \& Vendruscolo, 2012). 
Figura 1 - Mapa do Brasil, do Rio Grande do Sul e localização da Quarta Colônia/RS.

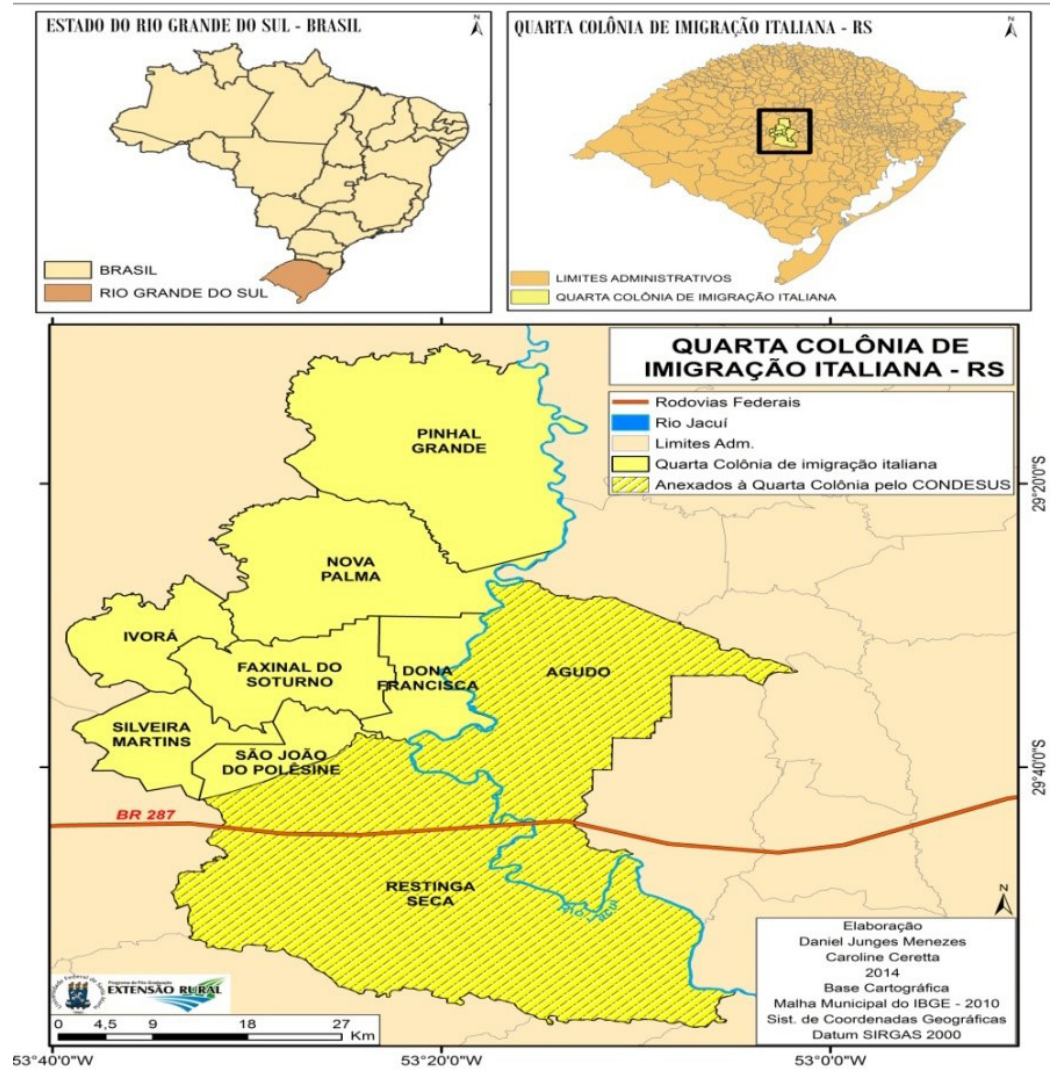

Fonte: Daniel Menezes e Caroline Ceretta (2014).

Historicamente, a agricultura segue sendo a principal atividade econômica da Quarta Colônia, apresentando uma estrutura fundiária formada por propriedades de agricultores familiares que possuem entre 20 e 30 hectares de terra (Neumann, 2003). O sistema produtivo é do tipo colonial e diversificado, baseado nos sistemas produtivos de leite, fumo, soja, arroz, batata inglesa, milho e bovino de corte. No entanto, embora esse sistema tenha enfraquecido entre os anos de 1950 e 1970 por conta da modernização produtiva que desencadeou um processo de marginalização socioeconômica no território, os anos de 1980 oportunizariam novas estratégias para o desenvolvimento do território, principalmente a partir da valorização de produtos agroalimentares por meio da produção agroindustrial, da atividade de turismo e de outras atividades comerciais para além da produção agrícola (Silveira et al., 2012).

Mesmo a agricultura familiar caracterizand o a base econômica dos municípios, nos últimos anos, outras iniciativas voltadas à valorização do patrimônio cultural e natural e do setor agroalimentar industrial foram acionadas para constituir uma mudança qualitativa das atividades sociais e produtivas do território em nome do seu desenvolvimento territorial. 
Nesse aspecto, a atividade de turismo tem sido um importante dispositivo de movimentação socioeconômica e valorativa do patrimônio natural e cultural entre os municípios, mobilizando os elementos culturais identitários encontrados na origem étnica dos primeiros imigrantes, no sentimento de italianidade rememorado, na religiosidade presente nos cultos e festas religiosas e na gastronomia típica local (Vendruscolo, 2009; Guimarães, 2011).

\section{DISCUSSÕES E RESULTADOS}

Os dados apresentados são resultantes das entrevistas realizadas com os gestores responsáveis pelas Secretarias de Turismo dos municípios da região estudada, sendo que a pesquisa contemplou a totalidade dos municípios da região, que é composta por nove municípios. A opção pela forma de abordagem por meio de entrevista com roteiro semiestruturado foi fundamentada pela flexibilidade na relação com o entrevistado, possibilidade de aprofundar as questões e, também, explorar outras questões surgidas no decorrer da entrevista (Malhotra, 2012). Para alcançar os objetivos propostos, foram abordadas questões referentes: (a) à gestão, com ênfase na estrutura administrativa, grupo de trabalho responsável pela área, elaboração de planejamento, organização de ações direcionadas ao turismo, ao orçamento, aos investimentos, à infraestrutura; e (b) às ações integradas, abordando as parcerias existentes e as perspectivas futuras para as atividades relacionadas ao turismo.

Constatou-se que todos os municípios da Quarta Colônia possuem em sua estrutura administrativa uma secretaria que responde pelas ações da atividade turística. Porém, estas secretarias atendem também outras atividades, tais como educação, indústria, comércio e desporto. O compartilhamento da competência em uma mesma secretaria destes diferentes setores produtivos foi motivado, principalmente, pela escassez de recursos financeiros e humanos. Na opinião de uma secretária, "isso ocorre em municípios menores pela falta de recursos financeiros o que impossibilita que a administração municipal possua mais setores e departamentos".

Referindo-se à quantidade e à qualificação de servidores municipais atuando no setor de turismo, verificou-se que, na maioria dos municípios, dois servidores são responsáveis pelas atividades, enquanto três municípios possuem apenas um 
servidor e em apenas um município não há servidores atuando especificamente no setor. Os servidores que atuam possuem experiência prática no setor e somente um município recentemente contratou um profissional com formação na área (turismólogo) para assumir o Departamento de Cultura e Turismo.

Dentre as funções desempenhadas pelos servidores, as mais recorrentes incluem organização, promoção e divulgação dos eventos do município, além de organização da própria secretaria e participação em reuniões sobre o turismo. Outro fator relevante a ser considerado em relação à gestão relacionase à efemeridade das ações e dos projetos, com atuação de curto prazo e de caráter passageiro, sem continuidade e planejamento de médio e longo prazo. Sendo assim, a organização e a divulgação dos eventos municipais são as principais atividades desempenhadas pelas secretarias responsáveis pelo setor de turismo.

Neste cenário de efemeridade e de poucos investimentos, a grande maioria dos entrevistados destaca que os projetos desenvolvidos e relacionados ao turismo nos municípios incluem somente a manutenção e as melhorias na infraestrutura, tanto para a construção quanto para reformas dos acessos e dos locais dos atrativos turísticos.

Os principais obstáculos para o exercício de uma administração profissional das atividades ligadas ao setor de turismo, apontados pelos gestores municipais, relacionam-se à falta de mão de obra especializada e à falta de recursos financeiros. Com um orçamento inexistente ou de pequeno valor, o poder público possui projetos incipientes e atua de forma precária. Na opinião dos gestores, o maior desafio das áreas de cultura e no turismo é que os administradores públicos não elegem estas atividades como prioridades; há carência de pessoal e de recurso, que são fundamentais para a execução de projetos; o principal empecilho é o orçamento curto; os obstáculos partem do básico: a falta de verba, a falta de tempo, a falta de pessoal e falta de estrutura; o que dificulta a atual gestão é a falta de recursos humanos e recursos financeiros; o principal obstáculo são as questões financeiras. A possibilidade de investimento esbarra na falta de verbas; a atividade turística nunca foi uma prioridade, porém a vocação da região é o turismo, o que se percebe é que os investimentos ainda são pequenos porque não há empresários que apostem muito nisso. 
A dificuldade financeira do setor de turismo nos municípios da Quarta Colônia fica evidenciada pela constatação de que não há dotação orçamentária específica para o turismo. Os valores aplicados nas atividades ligadas ao turismo nos municípios são destinados à secretaria a qual o setor faz parte e sua destinação disputada internamente.

Com relação ao planejamento da atividade turística, à importância e às perspectivas na região da Quarta Colônia, percebeu-se que, embora exista um movimento recente de alguns municípios para a constituição de Conselhos Municipais de Turismo, atualmente os municípios não possuem objetivos definidos para o turismo e, tampouco, elaboram planos para o desenvolvimento da atividade. A inexistência de planejamento reflete numa atuação sem estratégia definida, o que compromete a eficácia das ações. Relatos de gestores corroboram esta constatação quando dizem que o município procura trabalhar em cima do que já é feito, a fim de manter e aperfeiçoar; o turismo deve ser, em grande parte, exercido pela iniciativa privada, e o poder público deve servir como um apoiador; o turismo ainda está se estruturando, sendo assim, o turismo no município é pensado conforme a demanda, geralmente voltado aos eventos; a secretaria deve começar a pensar em um projeto, a disseminar o turismo, e assim divulgar o potencial do município com relação a essa atividade.

A opinião dos gestores em relação à importância do turismo para os municípios é divergente. Enquanto para alguns gestores entrevistados o turismo não é representativo: "O turismo ainda não gera impactos, pois a economia do município é essencialmente agrícola"; "atualmente, ele (o turismo) não gera retornos, pois ele não está acontecendo no município"; "o turismo ainda não possui muita importância no que se diz respeito a economia do município". Para a maioria dos entrevistados a atividade turística é considerada importante para o município. Ainda segundo os gestores municipais, a importância do turismo no município existe na medida em que ele tem o poder de gerar desenvolvimento e gerar mais empregos. Na opinião dos gestores: "o setor de turismo é significativo na questão de eventos," "tem importância vital, principalmente na alta temporada do balneário"; "se houverem mais investimentos partindo dos empreendedores, o turismo terá um ótimo cenário para o futuro, pois é a área com maior potencial de crescimento"; "é importante para a economia local, principalmente para os 
restaurantes do município"; e "o turismo é importante, mas ainda carece de valorização por parte dos moradores locais".

Quanto à evolução do turismo, nos municípios da Quarta Colônia a atividade se desenvolveu de maneiras diferentes. Enquanto um município estima que nos últimos cinco anos as atividades relacionadas ao turismo aumentaram mais de $100 \%$, outros três municípios também relataram que houve uma boa evolução e, nos municípios restantes, foi verificada uma estagnação das atividades relacionadas ao turismo.

Um aspecto positivo para o setor de turismo é a perspectiva positiva relatada por todos os entrevistados, ou seja, acreditam que seus municípios possuem potencial para atrair novos turistas. Neste quesito percebe-se que os municípios partem de diferentes estágios: alguns estão mais avançados no que se refere à gestão e à infraestrutura, enquanto outros estão iniciando este processo. Destaca-se que apenas um dos municípios não apresenta entusiasmo para a atividade, sendo que os demais acreditam que o turismo provavelmente exercerá maior influência econômica e social nos seus respectivos municípios.

Para a efetivação do avanço do setor do turismo nos municípios, segundo um dos gestores municipais entrevistados:

O turismo irá se desenvolver melhor quando surgir um empreendedor que invista e dê certo, e assim os nossos habitantes vejam que isso é possível; o turismo é uma engrenagem, a falta de conhecimento e o atraso o prejudicou, (...) então é necessário que ocorra planejamento e que se tenha uma continuidade por quem irá suceder os gestores; investindo em infraestrutura e divulgação.

Da mesma forma, ao referir-se ao poder público, outro gestor municipal responsável pela pasta do Turismo, em entrevista, considerou que:

O poder público não tem muito o que fazer, pois não há meios legais de investir em negócios privados; concedendo mais incentivos para o empresariado, aumentar o orçamento da pasta, para assim serem executados mais investimento em logística e infraestrutura; ter uma legislação vigente no município onde ele destina um valor especifico neste departamento com relação à recursos financeiros; deve-se atuar mais na manutenção, trabalhar com a ajuda das pessoas $e$ obter mais verbas. 
E, para finalizar, a visão de que a atividade de turismo necessita maior incentivo via comunicação, sendo esta a medida mais eficaz: "deve-se melhorar o município em todos os aspectos, prezando pelo desenvolvimento de maneira integrada entre todos os setores, assim irá atrair mais investidores"; "se o município pudesse usar outros meios de divulgação para os eventos, como a televisão, o turismo aumentaria aqui na cidade".

Quanto às ações integradas em torno do turismo, o território da Quarta Colônia inicialmente recebeu esta nomenclatura por representar uma identidade originada pela colonização italiana no Brasil e ser a quarta localidade a receber imigrantes da Itália no Rio Grande do Sul. Nesta região, em 1995, foi criado o Projeto de Desenvolvimento Sustentável da Quarta Colônia do RS (PRODESUS), que entrou em vigor em 1996. Segundo Souza (2009), este projeto teve como objetivo a condução de recursos para a qualificação dos técnicos que atuavam na região no intuito de auxiliar os agricultores da região. Assim foram desenvolvidos programas de implantação de florestas energéticas, recuperação de áreas degradadas, melhorias dos Hortos Municipais, criação de Roteiros Integrados de Turismo Rural, Cultural e Ecológico e Programas de Educação Patrimonial e Ambiental.

Para Marin (2010), o PRODESUS era composto por quatro projetos: a) Manejo dos Recursos Naturais da Quarta Colônia; b) Desenvolvimento da Agricultura Sustentável; c) Desenvolvimento do Turismo, Ecológico, Rural e Cultural; e, d) Programas de Educação Patrimonial e Ambiental.

A articulação para o desenvolvimento do município e da região e a criação do Consórcio de Desenvolvimento Sustentável da Quarta Colônia (CONDESUS) se deu pela necessidade do PRODESUS obter aceitação política e jurídica. Ele foi designado para responder necessidades administrativas, captar recursos e executar ações respaldadas nos recursos naturais e culturais provenientes da Quarta Colônia (Marin, 2010).

Adicionalmenteo autoracrescenta que"pode-se afirmarque o principal objetivo do CONDESUS/Quarta Colônia é ser um espaço de discussão de ações, projetos e programas de interesse territorial, que tenham como objetivo a integração e o desenvolvimento dos Municípios consorciados" (Marin, p. 169,2010). 
Outra organização de articulação dos municípios da região é a Associação dos Municípios do Centro do Estado (AMCentro), que é uma das 27 associações regionais organizadas pela Federação dos Municípios do Rio Grande do Sul (FAMURS), entidade que representa todos os 497 municípios gaúchos - reunindo prefeitos, vice-prefeitos, secretários, técnicos e órgãos da gestão pública municipal (AMCentro, 2016). Com o objetivo de fortalecer o municipalismo e garantir a representatividade dos agentes locais, as associações regionais discutem assuntos relacionados às diversas áreas de interesse dos municípios, apresentam demandas e alinham decisões. No setor de turismo, a FAMURS trabalha, junto aos municípios, na formulação de políticas voltadas à criação do Sistema Municipal de Turismo - que compreende o Conselho Municipal de Turismo, o Fundo Municipal de Turismo e o Plano Municipal de Turismo. Participa de órgãos do Governo do Estado, como o Conetur, defendendo ações focadas no desenvolvimento turístico regional. Também atua na estruturação de ações do Plano de Desenvolvimento do Turismo do Estado.

Com relação à existência ou não de ações integradas para o fortalecimento do turismo no território, na percepção dos responsáveis pelas Secretarias Municipais de Turismo, há discordância em termos da eficácia das ações do CONDESUS e da AMCentro. Para muitos não existe articulação regional visando ao desenvolvimento turístico de maneira integrada entre os municípios da Quarta Colônia. Alguns destacam a AMCentro como uma ferramenta para o desenvolvimento do turismo, enquanto outros citam o CONDESUS, porém é unânime a constatação de que, apesar da existência de algum tipo de articulação para o desenvolvimento do turismo, a atuação não tem refletido em projetos e ações concretas. Questionados sobre a existência de políticas públicas voltadas ao desenvolvimento integrado do turismo entre os municípios que compõem a Quarta Colônia, as respostas foram: "Sim, a regionalização do turismo feita pela AMCentro"; "Toda a regionalização desenvolvida na AMCentro"; "Sim, o CONDESUS (consórcio de desenvolvimento sustentável) da Quarta Colônia auxilia"; "Sim, através do CONDESUS"; 'Na prática não, na teoria sim, no caso seria o CONDESUS"; "Acredito que tenha"; "Sim, mas não é de maneira atuante"; "Sim, o CONDESUS apoia"; "Através da AMCentro, que é associação dos municípios, fazendo reuniões mensais com os diretores de turismo dos municípios, discutimos questões de projetos, cadastros". 
Entretanto, a única ação destacada como realizada no setor de turismo pelo CONDESUS foi descrita por uma Secretaria de Turismo: "Certa vez foi feito um panfleto, através do CONDESUS, e cada município recebeu então um kit contendo o turismo religioso, ecológico, cultural, gastronômico, e mais roteiros integrados".

No que se refere à realização de reuniões entre os representantes do setor de turismo dos municípios da Quarta Colônia para discutir sobre o desenvolvimento da atividade com ações conjuntas, constatou-se que atualmente não existem contatos para discutir o tema entre os municípios integrantes. Como os municípios fazem parte da região central, todos são integrantes da AMCentro e alguns municípios participam de reuniões que ocorrem mensalmente nesta associação, porém, apesar de serem convocados para reuniões que ocorrem mensalmente, nem todos os municípios que fazem parte da Quarta Colônia participam das reuniões promovidas por esta associação.

De acordo com a Secretaria de Turismo do Estado do Rio Grande do Sul, somente dois municípios da Quarta Colônia integram rotas turísticas (Setur, 2016). Entretanto, as rotas não representam ações integradas, pois são formadas com municípios de outras regiões e, segundo os gestores municipais entrevistados, tais rotas são pouco demandadas por turistas. Sobre a parte paleontológica, o gestor afirma que, por ser um local inédito na região, está sendo muito procurado e que daqui por diante prevê que as obras de infraestrutura comecem a deslanchar para aquele lado, acrescenta que essa área irá trazer no futuro muito desenvolvimento turístico para o município.

Dos municípios da Quarta Colônia que possuem roteiros turísticos que constam no site oficial da referida Secretaria Estadual, destaca-se o município de São João do Polêsine, que integra a Rota Paleontológica, composta pelos municípios de Porto Alegre, Santa Maria, São João do Polêsine, São Pedro do Sul e Mata. Nesta rota são apresentadas a história dos fósseis vegetais e animais, com originais e réplicas de seus acervos (Setur, 2016). Além deste, o município de Silveira Martins aparece compondo a Rota Turística e Gastronômica, juntamente com o município de Santa Maria. A rota proporciona um passeio através da natureza formada por belos vales e paisagens, pela história preservada nas construções do início do século, por seu povo acolhedor e fiel às origens e 
pela cozinha italiana nos cardápios dos restaurantes da região. Nesta rota está o Caminho da Uva e das Águas, que proporciona aos visitantes um contato com a natureza e a cultura locais, marcadas pela tradição dos descendentes de italianos que povoaram a região, berço da Quarta Colônia de Imigração Italiana no RS (Setur, 2016). No entanto, ambos roteiros passam por reestruturação para efetivar seus atrativos na atualidade.

Na percepção da maioria dos entrevistados a integração das atividades turísticas entre os municípios é deficiente, embora haja o entendimento da importância da união da região para o desenvolvimento da atividade turística. Todos acreditam que os seus municípios possuem potencial para atrair novos turistas, porém esbarram em alguns desafios que possuem em comum, tais como a infraestrutura (estradas de acesso precárias e falta de sinalização), poucos empreendimentos ligados ao setor de turismo (hotéis e restaurantes) e, principalmente, a inexistência de roteiros predefinidos para atrair mais visitantes. A falta de recursos financeiros/orçamento foi um desafio que também foi citado.

\section{CONSIDERAÇÕES FINAIS}

A estruturação do setor de turismo nos municípios estudados é precária em todos os quesitos pesquisados, observando-se as principais fragilidades na gestão das atividades do setor que é realizada por servidores que atendem outras áreas, poucos profissionais com formação acadêmica e com capacidade para formular estratégias para produtos turísticos, além de dedicação de tempo e de recursos deficientes, o que dificulta uma gestão mais apropriada e necessária para o desenvolvimento eficaz de projetos e ações.

A inexistência de um plano a nível municipal e regional, a falta de objetivos definidos para o desenvolvimento do turismo, juntamente com o não estabelecimento de estratégias, tanto municipais quanto regionais, enfraquecem a atividade e refletem a deficiência do setor nos municípios e na região estudada. Estas constatações vão de encontro à afirmativa de autores tais como Sacco dos Anjos \& Caldas (2009); Aranda et al. (2017) e Beni (2006) de que para o desenvolvimento do setor de turismo é muito importante a participação da 
administração pública, realizando o planejamento em nível macro, além da articulação e da coordenação dos diferentes atores que dinamizam o setor.

Nesta perspectiva destaca-se que na transformação provocada pela aliança pública-privada, a atividade turística requer a ação conjunta e integrada, que a médio e longo prazo podem superar a escassez pública de recursos financeiros, de empreendedorismo, de qualidade dos serviços e muitos outros fatores que afetam roteiros turísticos e suas estratégias competitivas. Alianças públicoprivadas pressupõem gestão compartilhada que minimizam os riscos de fracasso desde o processo de planejamento de roteiros turísticos, e que lamentavelmente ainda são visualizados em muitos locais. Assim, poder contar com o apoio das governanças locais públicas e privadas é uma oportunidade de articular roteiros turísticos de forma contínua, tanto em âmbito local como regional. Os atores locais, cientes dos desafios da atividade, podem ser protagonistas de roteiros turísticos ativos, numa política democrática e ascendente que dê liberdade de escolha entre os projetos, para que suas localidades não sejam constantemente palco de ações e experiências governamentais que são desarticuladas e substituídas por outras propostas (Beni, 2006; Sacco dos Anjos \& Caldas, 2009).

Considerando a afirmação de Aranda et al. (2017) de que as alianças público-privadas podem ser relevantes por compreender a percepção e a aceitação dos envolvidos e "sobre esta base se orienta cómo y en qué áreas se desarrolla un turismo local que implique mejoras socioeconómicas", percebese que, na opinião dos representantes da gestão pública na região estudada em relação às atividades pensadas para o turismo, evidencia-se a compreensão da necessidade de fortalecer a área, no entanto, os entrevistados apontam que faltam investimentos no setor de infraestrutura, serviços, divulgação. Nesse contexto, percebe-se uma contradição, a vocação da região é para o turismo, mas a ausência de investimento na contratação de mão de obra especializada e a escassez de recursos destinados para esse setor prejudicam o desempenho e o fortalecimento de ações efetivas.

Ressalta-se que a região da Quarta Colônia, segundo Setel (n.d.), possui belas paisagens e influências culturais relevantes, com potencial para oferta de produtos atrativos para turistas de diversos segmentos, comparando-se, 
especialmente, com outras regiões similares no sul do Brasil, tais como a região das Hortênsias e a Serra Gaúcha, que possuem uma infraestrutura e roteiros com grande afluência de turistas. Entretanto o turismo ainda não conquistou seu devido espaço entre as discussões em torno do desenvolvimento da Quarta Colônia. Evidenciou-se que tal situação decorre, principalmente, porque ainda não há um reconhecimento adequado da capacidade de o turismo gerar novas atividades e acionar setores, tais como o de serviços e outros que podem contribuir de forma efetiva no desenvolvimento socioeconômico. Quanto às ações integradas, pode-se dizer que estas giram em torno de iniciativas pontuais, sem um planejamento conjunto de médio e longo prazo para atividades promocionais do turismo da região.

Numaanálise amplasobre oturismo na região da Quarta Colônia/RS, percebese que o poder público possui uma atuação discreta nas atividades direcionadas ao turismo, com ações desarticuladas, dispersas e com planejamento precário. Considerando que a atividade turística, alicerçada numa política que prime pela sustentabilidade pode ser entendida como potencializadora do campo social, cultural, econômico e ecológico, influenciando de maneira significativa nas comunidades, por meio da geração de emprego e renda, melhoria na qualidade de vida, oferta de bens e serviços, entre outros benefícios, inferese que um dos caminhos que possa ser apontado nesse estudo para uma mudança de cenário, seja o fortalecimento das relações público/privado, o desenvolvimento de parcerias na organização de cursos/capacitações para os agentes que atuam nessa área, o planejamento de ações de divulgação e, acima de tudo, o envolvimento dos moradores de cada localidade como elemento fundamental no processo de construção, manutenção de ações em prol do turismo desta região.

Alguns fatores restringiram uma análise mais aprofundada do tema abordado pela falta de tempo por parte dos gestores para conceder a entrevista; falta de um servidor responsável somente pelo turismo; a constatação de que a maioria dos entrevistados não possui experiência e/ou formação acadêmica em turismo ou em áreas relacionadas, o que restringiu a explicação de fenômenos existentes, ocasionando a obtenção de respostas fora de contexto e a simplificação dos problemas existentes, relacionando-os à falta de recursos financeiros 
ISSN: 1983-7151

disponibilizados para o setor e as constantes alterações de programas e projetos que ocorrem a cada quatro anos, quando da mudança de responsáveis pelas Prefeituras Municipais.

\section{REFERÊNCIAS}

AMCentro. (2016). Associação dos Municípios do Centro do Estado do RGS. Disponível em: http://www.famurs.com.br/associacoes/AMCENTRO. Acesso em 10/02/2016.

Aranda, M.F; Álvarez, W.T.S.; Alcívar, L.D.A.; Suárez, Y.P. (2017). Alianzas público privadas para el desarrollo turístico local. Visión comparada Cuba- Ecuador. PODIUM Sport, Leisure and Tourism Review. Vol.6, N. 1 Janeiro/Abril.

Bahl, M. (2004). Viagens e Roteiros Turísticos. Protexto, Curitiba.

Beni, M. C. (2006). Política e planejamento de turismo no Brasil. Aleph, São Paulo.

Cooper, C. (2007). Turismo: princípios e práticas. Bookman, Porto Alegre.

Froehlich, J. M.; Vendruscolo, R.A. (2012). Construção social da identidade territorial Quarta Colônia: tramas e sentidos da narrativa. In: FROEHLICH, J. M. (Org.). Desenvolvimento territorial: produção, identidade e consumo. Ijuí, RS: Ed. da Unijuí, p. 305-352.

Froehlich, J. M.; Alves, H. F. I. (2007). Novas identidades, novos territórios: mobilizando os recursos culturais para o desenvolvimento territorial. Revista Extensão Rural. N. 14 (Jan/Dez): 65-90. Disponível em: http://w3.ufsm.br/extensaorural/art3ed14.pdf. Acesso em 25/11/2015.

GIL, A. C. (2009). Como elaborar projetos de pesquisa. São Paulo: Atlas.

IBGE. (2012). Instituto Brasileiro de Geografia e Estatística. Censo Demográfico 2010. Resultados do universo. Disponível em: <http://www.ibge.gov.br>. Acesso em: 20 jan. 2016.

Jasper, J. R. (2012). Roteiros Turísticos Rurais: um estudo de caso do Roteiro Turístico Delícias da Colônia-Estrela, Colinas e Imigrante (RS). In: Ceretta, C. C.; Jasper, J. R. (Orgs.) Turismo no espaço rural: oportunidades e sinergias contemporâneas. Editora da UFPEL, Pelotas.

Kotler, P.; Haider D. H.; Philip Kotler, Rein, I.; Gertner, D. (2006). Marketing de lugares: como conquistar crescimento de longo prazo na América Latina e no Caribe. Tradução Ruth Bahr. São Paulo: Prentice Hall.

Malhotra, N.K. (2012). Pesquisa de marketing: uma orientação aplicada. Porto Alegre: Bookmann. 
Marin, M. Z. (2010). Políticas de Desenvolvimento Rural e Estratégias de Reprodução na Agricultura Familiar da Quarta Colônia - RS. Tese de Doutorado em Desenvolvimento Regional e Urbano. Universidade Federal de Santa Catarina, Florianópolis.

Neumann, P. S. (2003). O impacto da fragmentação e do formato das terras nos sistemas familiares de produção. Tese de Doutorado. Universidade Federal de Santa Catarina, Florianópolis.

Nogueira, C. R. D. \& Burkhard, D. (2008). Políticas públicas de turismo para o desenvolvimento local/regional das Missões Jesuítico-Guarani. Revista Eletrônica de Turismo Cultural 02: 1-32 Disponível em: https://goo.gl/9vbo65 Acesso em 20/03/2016.

Pecqueur, B. (2005). O desenvolvimento territorial: uma nova abordagem dos processos de desenvolvimento para as economias do Sul. Raízes 24(01-02): 10-22.

Prefeitura Municipal de São Miguel das Missões (2016). História de São Miguel das Missões. Disponível em: http://www.saomiguel-rs.com.br Acesso em 23/03/2016.

Sabourin, E. (2009). Camponeses do Brasil: entre a troca mercantil e a reciprocidade. Trad. Leonardo Milani. Rio de Janeiro: Garamond.

Sacco dos Anjos, F. \& Caldas, N. V. (2009). A propósito do debate sobre pluriatividade e multifuncionalidade na agricultura: o surgimento de uma nova formação discursiva. Revista Theomai, 20(02): 22-33 Disponível em: https://goo.gl/GkGhrR Acesso em 22/03/2016.

Sacco dos Anjos, F. (2003). Agricultura familiar, pluriatividade e desenvolvimento rural no sul do Brasil. Editora da UFPel, Pelotas.

Sacco dos Anjos, F. (2011). Indicações geográficas, identidade e desenvolvimento: um diálogo entre a realidade europeia e brasileira. In: Froehlich, J. M. (Org.) Desenvolvimento territorial: produção, identidade e consumo. Editora da Unijuí, Ijuí.

Sampiere, R.H.; Collado, C.H.; Lucio P.B. (2013). Metodologia da pesquisa. Porto Alegre: Penso.

Setel. (n.d.). Secretaria do Turismo Esporte e Lazer do Rio Grande do Sul. Disponível em: http://www.setel.rs.gov.br. Acesso em 23/03/2016.

Setur. (2016). Turismo no Rio Grande do Sul. Disponível em: http://www.turismo.rs.gov.br/ roteiros/. Acesso em 10/04/2016.

Silva, A. P. da. (2014). Turismo e desenvolvimento territorial na Quarta Colônia, RS/ Brasil: uma abordagem na perspectiva do capital social. Tese de Doutorado em Extensão Rural. Universidade Federal de Santa Maria, Santa Maria. 
Silveira, P. R. C. et al. (2012). Identidades socioculturais e sistemas agroalimentares localizados: o percurso da Quarta Colônia, RS - Brasil. In: Froehlich, J. M. (Org). Desenvolvimento territorial: produção, identidade e consumo. Ijuí: Ed. da Unijuí, 2012. p. 353-383.

Souza, C. S. (2009). Plano Diretor da Quarta Colônia/ RS: desafios de pensar a noção de região. XIV Congresso Brasileiro de Sociologia, Rio de Janeiro.

Tavares, A. (2002). City tour. Aleph, São Paulo.

Triviños, A. N. S. (2011). Introdução à pesquisa em ciências sociais: a pesquisa qualitativa em educação - o Positivismo, a Fenomenologia, o Marxismo. São Paulo: Atlas.

Vendruscolo, R. (2009). Somos da Quarta Colônia: os sentidos de uma identidade territorial em construção. 2009. 209p.Dissertação de Mestrado em Extensão Rural. Universidade Federal de Santa Maria. Santa Maria.

WTTC. (2016). World Travel and Tourism Council. The Economic Impact of Travel \& Tourism: 2016 Annual Update. London Disponível em: https://goo.gl/pSAkhL. Acesso em 10/04/2016.

Zamberlan, C. O.; Schuch jr, V.F.; Alves, F.D.; Sonaglio, C.M. (2007). Formação de Associações Cooperativas ou Redes de Empresas: um estudo com produtores de hortifrutigranjeiros e de produtos coloniais localizados na microrregião da Quarta Colônia do RS. Anais do $45^{\circ}$ Encontro da Sociedade Brasileira de Economia e Sociologia Rural, Londrina.

\section{CONTRIBUIÇÃO DOS AUTORES NA CONSTRUÇÃO DO ARTIGO}

DOTTO: análise dos dados, redação do resumo, introdução, contextualização teórica, considerações finais e ajustes solicitados pelos avaliadores.

DENARDIN: coleta de dados e análise dos dados.

PONS: revisão.

CERETTA: contextualização teórica, redação e ajustes finais. 